Manuscript received June 14, 2017; accepted for publication November 20, 2017; published online June 19, 2018.

1 Mechanical Engineering Department, Pakistan Navy Engineering College, National University of Science and Technology, Houser No. R-149/A, Block 3, Gulistan-e-Jauha, Karachi, Pakistan (Corresponding author), e-mail: behzad_zai@pnec.nust. edu.pk, (1) https://orcid.org/ 0000-0002-2584-9006

2 School of Aerospace, Cranfield University, Cranfield, UK

3 Department of Mechanical Engineering, Myongji University, Yongin, South Korea

${ }^{4}$ Advanced Material Research Division, Space and Upper Atmosphere Research Commission, Karachi, Pakistan
Behzad Ahmed Zai, ${ }^{1}$ M. A. Khan, ${ }^{2}$ M. K. Park, ${ }^{3}$ Majid Shahzad, ${ }^{4}$ M. A. Shahzad, ${ }^{3}$ Salman Nisar, ${ }^{5}$ S. Z. Khan, ${ }^{6}$ Kamran Khan, ${ }^{7}$ and Aqueel Shah ${ }^{8}$

\section{Low-Velocity Impact Characterization of Fiber-Reinforced Composites with Hygrothermal Effect}

\section{Reference}

Zai, B. A., Khan, M. A., Park, M. K., Shahzad, M., Shahzad, M. A., Nisar, S., Khan, S. Z., Khan, K., and Shah, A., "Low-Velocity Impact Characterization of Fiber-Reinforced Composites with Hygrothermal Effect," Journal of Testing and Evaluation, Vol. 47, No. 1, 2019, pp. 350-360, https://doi.org/10.1520/JTE20170620. ISSN 0090-3973

\section{ABSTRACT}

In this article, low-velocity impact characteristics of UHN125C carbon fiber/epoxy composite, including unidirectional $\left(0^{\circ}\right)$, cross-directional $\left(0^{\circ} / 90^{\circ}\right)$, and quasiisotropic layups, were experimentally measured. The effect of the fiber orientation angle and stacking sequences on impact force and induced strain were measured via an instrumented drop-weight apparatus with special concern for the moisture absorption effect. Dried specimens were immersed in distilled water for a certain period of time to absorb water for intermediate and saturated moisture content. It was observed that the impulse was reduced with the increase in moisture content; on the other hand, strain increased with moisture, as measured by DBU-120A strainindicating software (MADSER Corp., El Paso, TX). Impact damage is widely recognized as one of the most detrimental damage forms in composite laminates because it dissipates the incident energy by a combination of matrix damage, fiber fracture, and fiber-matrix debonding. Therefore, it is extremely important to know the impact strength of a structure, especially for applications in industries such as aerospace, ship design, and some other commercial applications. The use of composite materials in engineering applications is increasing rapidly because they have higher strength-to-weight ratios than metals. The strength, stiffness, and, eventually, the life of composite materials are affected more than conventional materials by the presence of moisture and temperature. Thus, it is necessary to analyze the response of composites in a hydrothermal environment. 
${ }^{5}$ Industrial and Manufacturing Department, Pakistan Navy Engineering College, National University of Science and Technology, Islamabad, Pakistan

${ }^{6}$ Mechanical Engineering Department, Islamic University of Madinah, Madinah, Saudi Arabia, (1) https://orcid.org/0000-00019023-2689

${ }^{7}$ Aerospace Engineering Department, Khalifa University of Science Technology and Research, Abu Dhabi, United Arab Emirates

${ }^{8}$ Mechanical Engineering Department, Pakistan Navy Engineering College, National University of Science and

\section{Keywords}

impulse, dynamic strain, layup, moisture content, fiber orientation

\section{Introduction}

Fiber-reinforced composite materials have been increasingly used in load-bearing structures because of a number of advantages they have, such as high specific strength and stiffness, good fatigue performance, and corrosion resistance, over more conventional materials [1]. Carbon fiber is a material that consists of extremely thin fibers that measure about $0.0002-0.0004$ in. $(0.005-0.010 \mathrm{~mm})$ in diameter and are composed mostly of carbon atoms.

The carbon atoms are bonded together in microscopic crystals that are more or less aligned parallel to the long axis of the fiber. The crystal alignment makes the fiber incredibly strong for its size. Carbon fiber can be combined with epoxy and then wound or molded to form composite materials, such as carbon fiber-reinforced plastic (also referred to as carbon fiber), to create a high strength-to-weight ratio material.

The need to develop and use light-weight structural components in the design of aircraft, automotive, and various sporting goods has brought increased application of composite material. Reliable performance of the advanced, high-strength material in critical applications depends on ensuring that each part placed in service satisfies the conditions selected in design. It is therefore necessary to ensure the quality of materials used and the integrity of the product during various stages of manufacturing as well as the final product.

A serious obstacle to the widespread utilization of composite laminates is its sensitivity to impact and static loads in the direction of thickness [2,3]. Low-velocity impact tests are often simulated by simple static indentation-flexure tests, which neglect the influence of dynamic effects on the structural response [4,5]. In epoxy-based laminates, static and dynamic tests are observed to produce the same damage modes and comparable force-deflection behavior [6]. Low-velocity impact is one of the most subtle threats to composite materials in aeronautics, owing to the weak bonds between the plies; even small energies imparted by out-of-plane loads can result in hardly detectable damages, causing considerable strength losses in tension and, especially, in compression [7].The energy absorbed during impact is mainly dissipated by a combination of matrix damage, fiber fracture, and fiber-matrix debonding. This may lead to significant reductions in the load-carrying capability of the laminate. Generally, the earliest observable damage affecting a laminate subjected to low-velocity impact is delamination, which is mainly responsible for compression strength impairment. For this reason, much research work has been devoted to the mechanisms of delamination initiation and growth [8-11]. Since the residual material properties after impact are of primary concern in applying damagetolerance concepts, many authors have also tried to correlate analytically or experimentally the residual tension and compression strength with impact energy and damage mechanisms [12,13]. The problem of calculating the maximum contact force has also been addressed extensively by other authors who used spring-mass models or the principle of conservation of energy [14,15]. Fewer data are available on the penetration process and related energy at low velocity although this phenomenon has received considerable attention in the domain of moderately high-velocity or ballistic conditions [16]. 


\section{Theoretical Analysis}

\section{IMPULSE}

Using an oscilloscope, an impact force response with respect to time can be obtained, as shown in Fig. 1, and will later be expanded for measuring the impact response of first striking, excluding noise and rebound.

The first impact with the force plate, which is area under the curve $P_{\max }$, can be simplified to a triangle in order to find the impact energy, as shown in Fig. 1. By the area of a triangle as shown in Eq 1, $P_{\max }$ is the maximum impact force.

$$
I=\frac{1}{2}\left(P_{\max }\right)(\text { Time })
$$

\section{IMPACT ENERGY}

Impact energy represents the amount of work that can be performed by a single blow of a hammering mechanism. This is called potential energy, and the force is called a restoring force. As a general rule, Eq 2 represents the work done by a conservative force. For this particular experiment, the impact energy will be same for all tests.

$$
\begin{gathered}
W=-\Delta P E \\
\Delta P E=m g \Delta h
\end{gathered}
$$

where $W$ is the work done, $P E$ is $m g h, \triangle P E$ is the change in potential energy, $m$ is the mass of the striker, $g$ is the gravitational acceleration, and $h$ is the height above impact surface.

\section{FIG. 1}

Impact force response for a particular specimen.

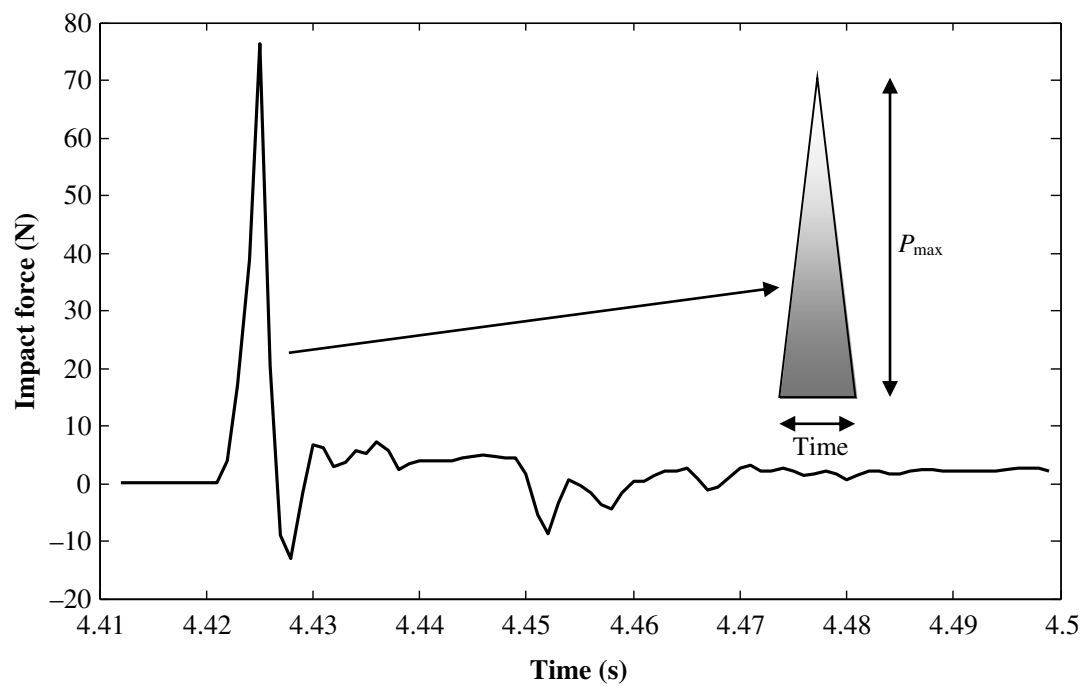




\section{Specimen Preparation}

\section{PROCESSING OF LAMINATES}

Three laminates of different stacking sequences were produced using unidirectional carbon/epoxy prepreg tape that was $0.113 \mathrm{~mm}$ thick. They were manufactured with high-strength carbon fiber that had a UHN125C grade, $39.32 \mathrm{GPa}$ tensile modulus, 4.61 GPa tensile strength, $1.82 \times 10^{-3} \mathrm{~g} / \mathrm{mm}^{3}$ fiber density, and $1.2 \times 10^{-3} \mathrm{~g} / \mathrm{mm}^{3}$ resin density. Three different layup sequences $\left(0^{\circ}\right.$ unidirectional, $0^{\circ} / 90^{\circ}$ cross-directional, and quasi-isotropic layup) were experimentally examined, as given in Table 1.

Before putting layup in the autoclave for curing, a vacuum bagging process for carbon/epoxy laminates needed to made, as shown in Fig. 2. Once the vacuum was achieved, laminates were simultaneously cured in the autoclave at $125^{\circ} \mathrm{C}$ and $0.49033 \mathrm{MPa}$, according to the curing cycle as shown in Fig. 3. Initially, a square plate that measures 300 by $300 \mathrm{~mm}$ was fabricated and was later cut using a low-vibration wheel cutter in order to get the specimen of desired dimension. The composite laminates consisted of eight plies, resulting in nominal thickness of $\sim 0.96 \mathrm{~mm}$; the final specimen was a square plate measuring 127 by $127 \mathrm{~mm}$.

\section{HYGROTHERMAL EFFECT}

In order to investigate the hot-wet environmental effect, the specimens were exposed to both temperature and moisture using a CW-20G refrigerating bath circulator (Jeio Tech Co., Ltd, Seoul, South Korea).

\section{TABLE 1}

Specimen layup sequence.

\begin{tabular}{lcc}
\hline Specimen Number & Specimen Layup Sequence & Description \\
\hline 1 & {$\left[0_{8}\right]$} & Unidirectional \\
2 & {$[0 / 90 / 0 / 90]_{\mathrm{S}}$} & Cross-ply \\
3 & {$[0 / 45 /-45 / 90]_{\mathrm{S}}$} & Quasi-isotropic \\
\hline
\end{tabular}

\section{FIG. 2}

Vacuum bagging process for graphite/epoxy composites.

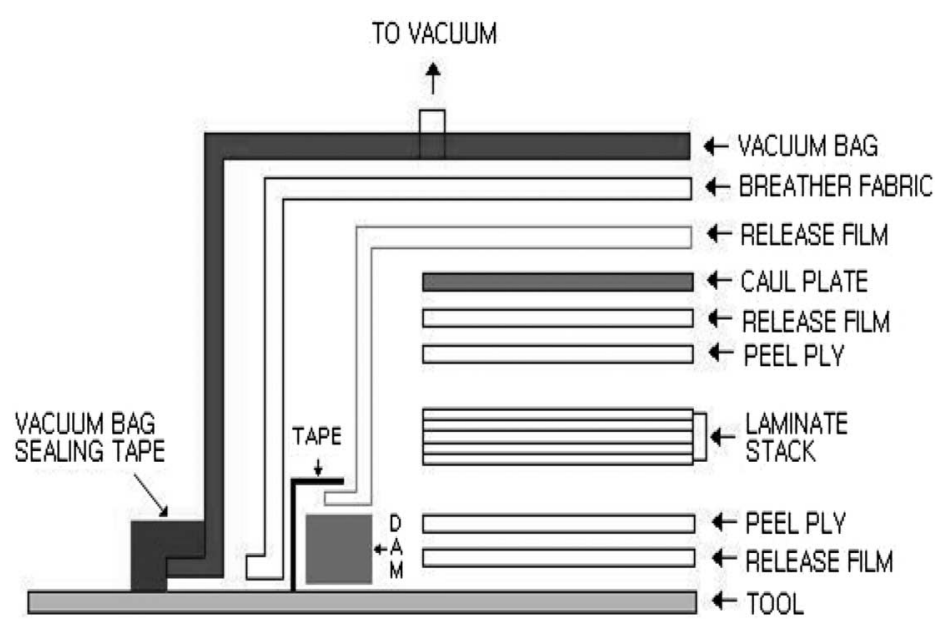


FIG. 3

Curing cycle in autoclave.

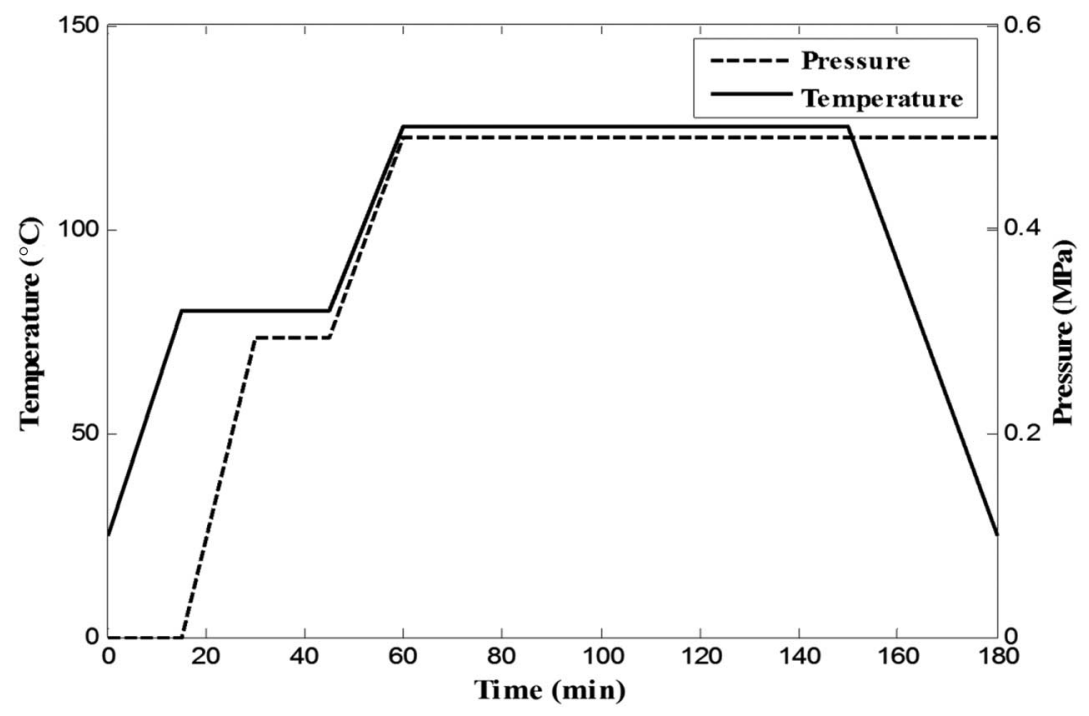

We followed these steps:

(1) Dry the specimens in the oven at $50^{\circ} \mathrm{C}$ to remove all moisture.

(2) Immerse the specimens in distilled water at $80^{\circ} \mathrm{C}$ for $8,16,24$, and 35 days for different moisture contents, which were calculated using Eq 4.

(3) Dry the sample for a short period of time before impact testing.

$$
M \%=\frac{W_{m}-W_{d}}{W_{d}} \cdot 100
$$

where, $M$ is the moisture content, $W_{m}$ is the weight of the wet sample, and $W_{d}$ is the weight of the dry sample.

\section{Strain Measurement and Experimentation}

\section{DYNAMIC STRAIN MEASUREMENT}

Strain gauges are excellent for the measurement of dynamic strain processes. Mounting one strain gauge on each square plate, as shown in Fig. 4, allows the measurement of maximum strain in the specimen close to the impact load at $0^{\circ}, 45^{\circ}$, and $90^{\circ}$. The gauge is mounted on a specimen under preload conditions, and the dynamic strain is measured using DBU-120A software. When the striker falls on the specimen, the striker penetrates it and the specimen splits. The measured strain is a long peak curve.

\section{EXPERIMENTAL SETUP}

The actual experimental setup and block diagram are shown in Figs. 5 and 6 . Low-energy impact tests were conducted on samples that measure 127 by 127 by $0.96 \mathrm{~mm}$ in a Dynatup/GRC minitower drop-impact machine (Instron, Norwood, MA) with a striker mass of $2.02 \mathrm{~kg}$. The specimen was placed on a rectangular plate that had a hole in the center and was fixed from the corners. The impact machine is equipped with a 
FIG. 4

Strain gauges set up on a square plate.

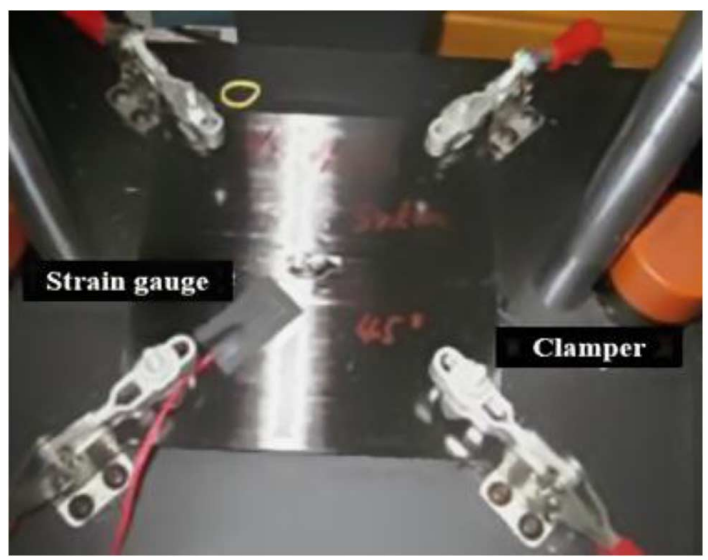

\section{FIG. 5}

Block diagram of complete experimental setup.

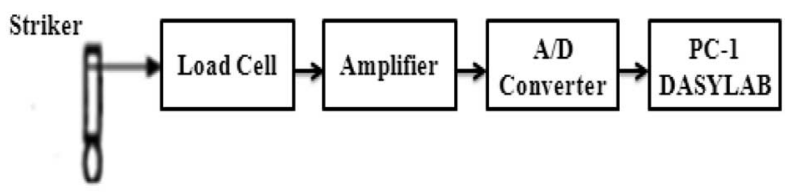

Specimen

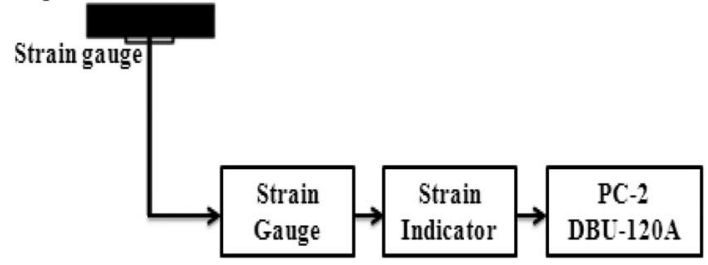

hemispherical nose of $12.7 \mathrm{~mm}$ diameter with rebound effect. The height of the striker was fixed $(445 \mathrm{~mm})$ with a falling velocity of $3.0 \mathrm{~m} / \mathrm{s}$. A piezometer load cell was placed on the upper part of hemispherical nose with the amplifier; the signals were recorded on a computer using DASYLab software (Measuring Computing Corp., Norton, MA) via A-D converter, as shown in Fig. 6.

\section{Results and Discussion}

Twenty-seven specimens were tested, and a total of nine specimens for each layup are mentioned in Table 1. Out of the nine specimens, three specimens were taken for each of three conditions (dry, intermediate, and saturated) and their mean value was considered. Moisture absorption takes place through a diffusion process governed by Fick's law, in which water molecules are transported from areas with higher moisture concentration to areas with lower moisture concentration $[17,18]$. Fig. 7 shows the weight increase as a function of exposure time. Like any other polymers, epoxies can absorb moisture when 
FIG. 6

Complete experimental setup.

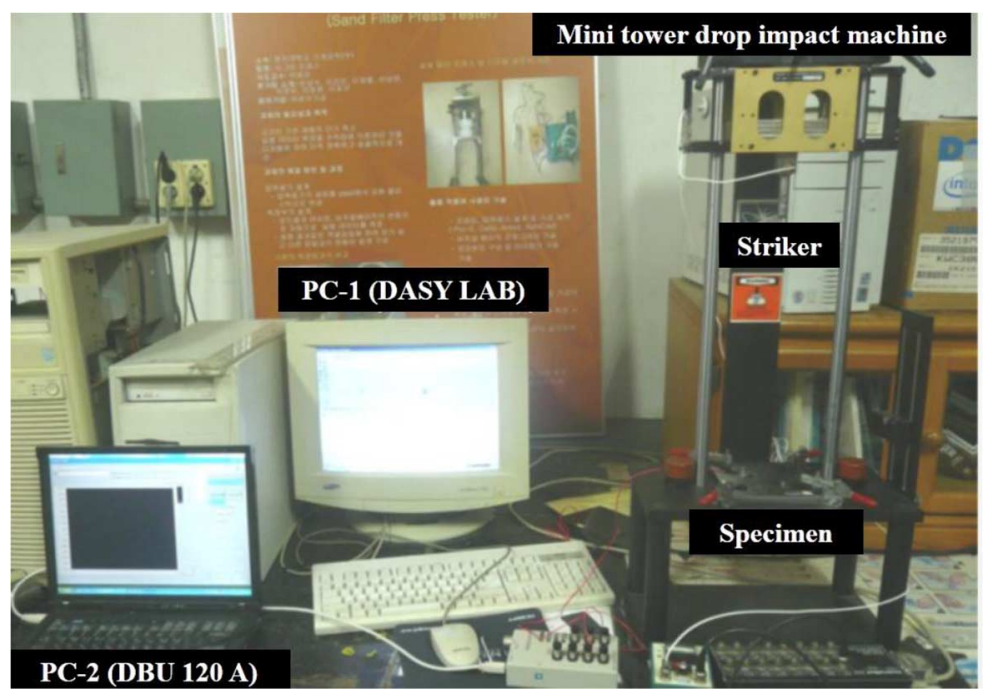

\section{FIG. 7}

Weight increase in terms of moisture content.

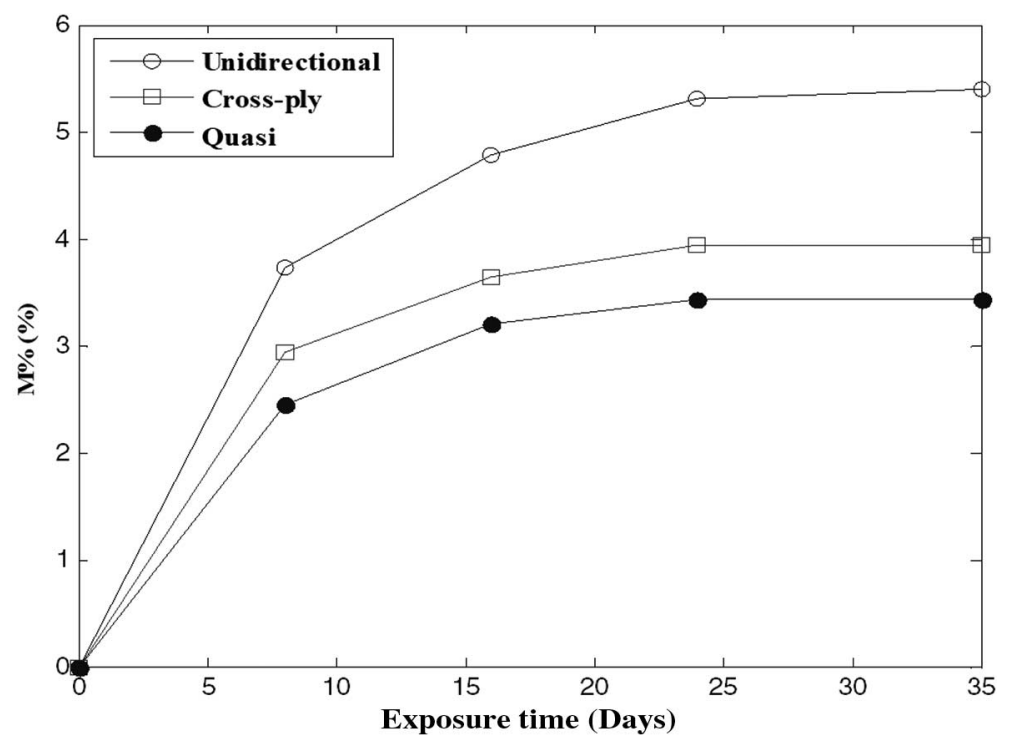

exposed to humid environments. From the results, it was found that the moisture absorption was not uniform: the unidirectional composites lead to absorption of $5.4 \%$, cross-ply composites with $3.9 \%$, and quasi-isotropic with $3.4 \%$. Similar results were obtained for moisture contents in previous research with different structures of the same composite [19]. From Fig. 7, it can be observed that the specimen's intermediate and saturated moisture content are at the exposure time of 8 and 35 days, respectively.

In the first experimental phase, the dynamic strain was measured, and the results were compared. Moreover, the strain variation that was due to the hygrothermal effect was 
TABLE 2

Experimental results for all specimen types with moisture content.

\begin{tabular}{|c|c|c|c|c|c|}
\hline Moisture & Specimen Type & Mass [g] & Moisture \% [\%] & Impulse [N-sec] & Strain $[$ micro $\mathrm{m} / \mathrm{m}$ ] \\
\hline \multirow[t]{3}{*}{ Dry layup } & $0^{\circ}$ & 24.56 & - & 3.78 & $2,172.7$ \\
\hline & $0^{\circ} / 90^{\circ}$ & 24.81 & - & 4.51 & $1,842.6$ \\
\hline & Quasi & 24.68 & - & 5.68 & $1,640.9$ \\
\hline \multirow[t]{3}{*}{ Intermediate moisture } & $0^{\circ}$ & 24.86 & 1.61 & 3.12 & $2,415.7$ \\
\hline & $0^{\circ} / 90^{\circ}$ & 25.14 & 1.32 & 4.00 & $2,011.5$ \\
\hline & Quasi & 25.08 & 1.24 & 4.92 & $1,806.1$ \\
\hline \multirow[t]{3}{*}{ Saturated moisture } & $0^{\circ}$ & 24.74 & 1.76 & 2.57 & $2,587.6$ \\
\hline & $0^{\circ} / 90^{\circ}$ & 25.02 & 1.46 & 3.48 & $2,218.5$ \\
\hline & Quasi & 24.89 & 1.34 & 4.29 & $1,978.0$ \\
\hline
\end{tabular}

FIG. 8 Strain measurement for dry specimens.
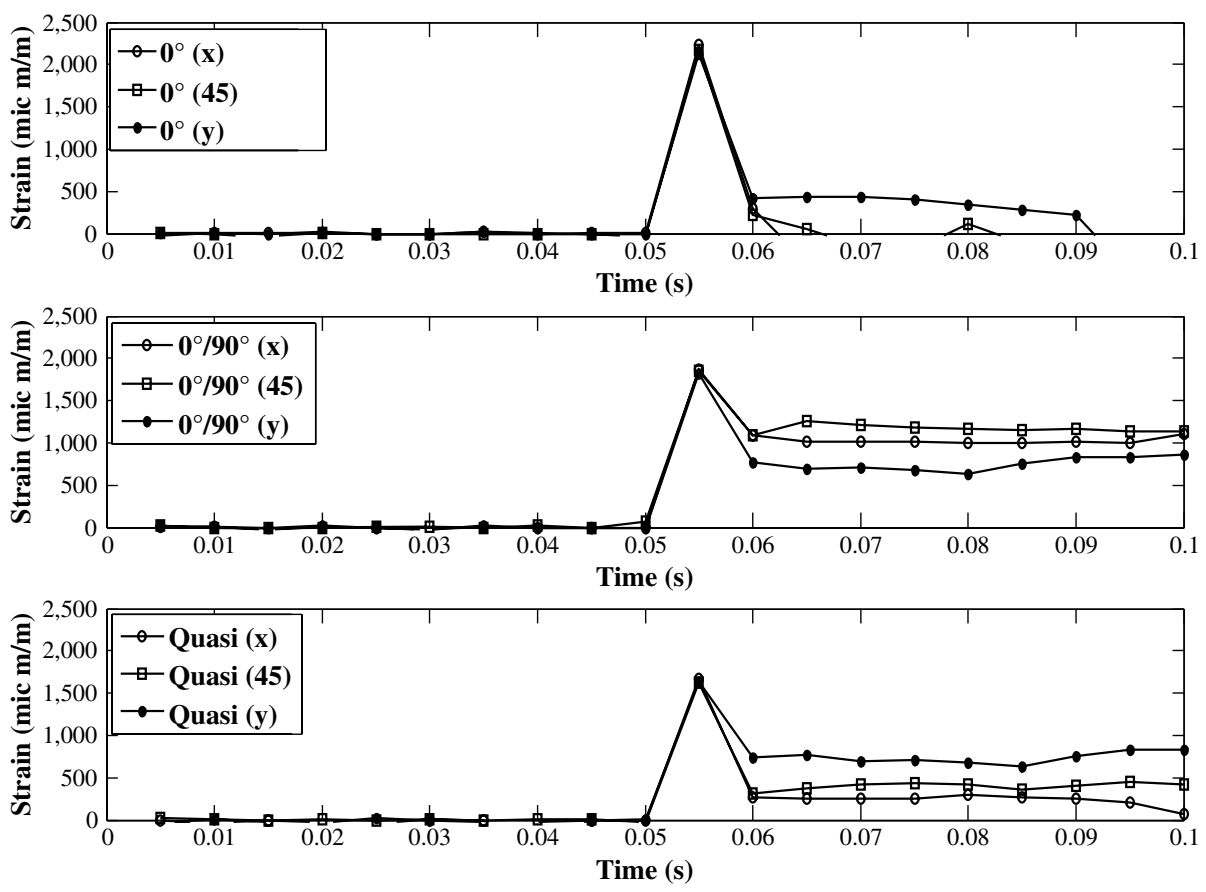
FIG. 9

Variation in strain for three layups with moisture content.

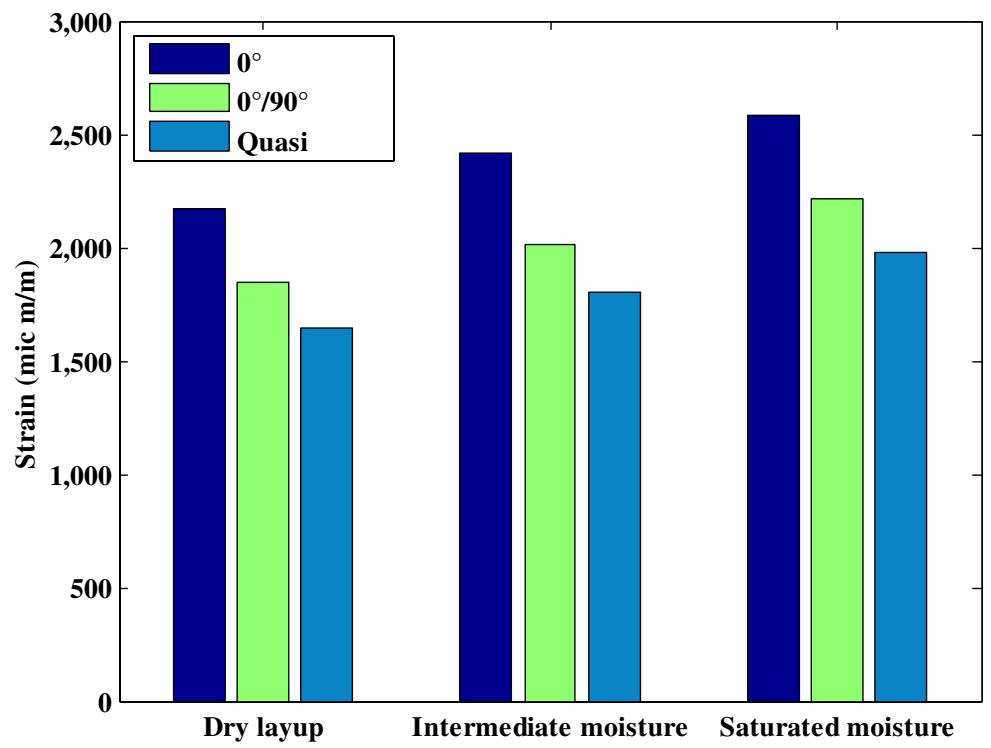

FIG. 10 Impulse force measurement in dry specimens.
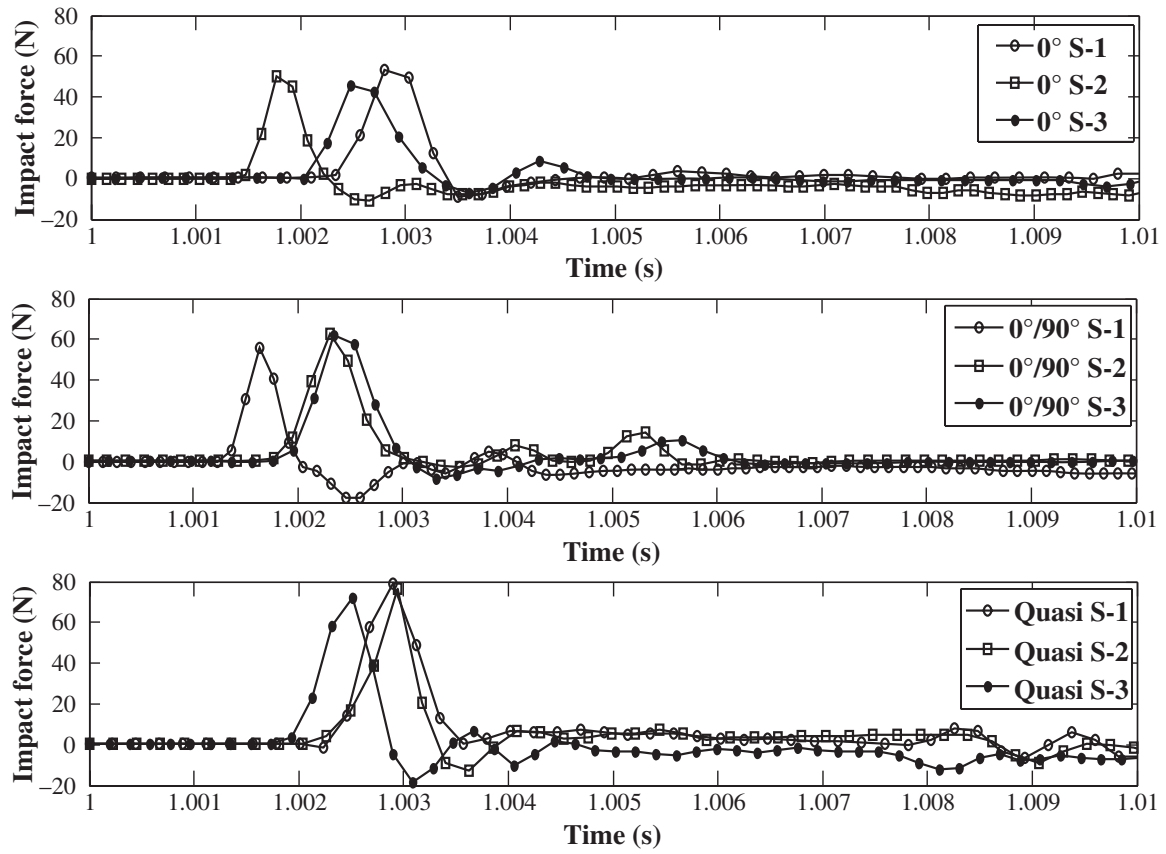

so it produced maximum strain, and it was expected that its impact response would be the lowest. Moisture and temperature minimize the impact force and therefore a lower impulse was obtained for intermediate and saturated moisture content. The hygrothermal effect gradually reduces the impulse and increases the strain. 
FIG. 11

Variation in impulse for three layups with moisture.

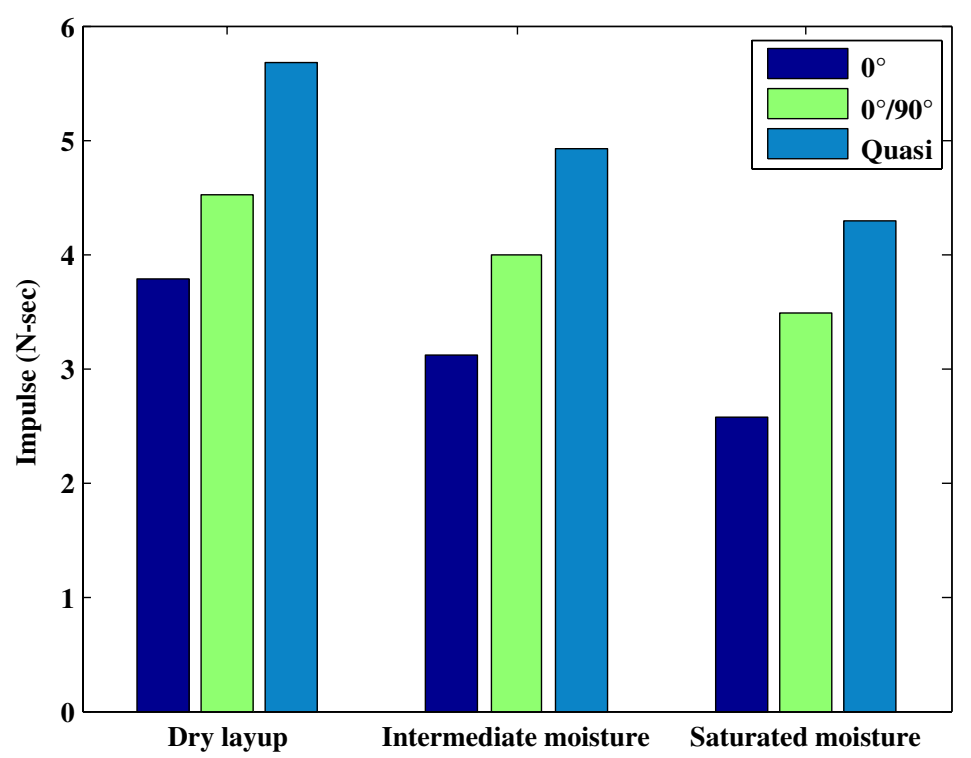

\section{Conclusion}

From this research on carbon fiber-reinforced composites, the following conclusion can be derived.

(1) Water absorptivity in unidirectional laminates was found to be higher than in cross-ply and quasi-isotropic laminates.

(2) During low-velocity impact tests, higher impulses were found in dry laminates in all stacking sequences; with the increment of moisture content, a reduction in impulse was observed.

(3) As far as the stacking sequence is concerned, the impulses in quasi-isotropic laminates were found to be much higher than in other stacking sequences in all proposed conditions.

(4) With the increment in moisture content, higher strain was found in all layups.

(5) Strain found in quasi-isotropic laminates was lower than unidirectional and crossply laminates in all proposed conditions.

\section{References}

[1] Aymerich, F., Priolo, P., and Vacca, D., "Static Loading and Low-Velocity Impact Characterization of Graphite/PEEK Laminates," presented at the International Conference on Advanced Materials (ICAC'98), Hurghada, Egypt, Dec. 15-18, 1998.

[2] Abrate, S., "Impact on Laminated Composite Materials," Appl. Mech. Rev., Vol. 44, No. 4, 1991, pp. 155-190, https://doi.org/10.1115/1.3119500

[3] Abrate, S., "Impact on Laminated Composites: Recent Advances," Appl. Mech. Rev., Vol. 47, No. 11, 1994, pp. 517-544, https://doi.org/10.1115/1.3111065

[4] Lagace, P. A., Williamson, J. E., and Tsang, P. H. W., "A Preliminary Proposition for a Test Method to Measure (Impact) Damage Resistance," J. Reinf. Plast. Compos., Vol. 12, No. 5, 2016, pp. 584-601, https://doi.org/10.1177/073168449301200508 
[5] Kwon, Y. S. and Sankar, B. V., "Indentation-Flexure and Low-Velocity Impact Damage in Graphite Epoxy Laminates," J. Compos. Technol. Res., Vol. 15, No. 2, 1993, pp. 101-111, https://doi.org/10.1520/CTR10361J

[6] Lesser, A. J. and Filippov, A. G., "Kinetics of Damage Mechanisms in Laminated Composites," presented at the 36th International SAMPE Symposium and Exhibition, San Diego, CA, April 15-18, 1991, pp. 886-900.

[7] Caprino, G., Lopresto, V., Scarponi, C., and Briotti, G., "Influence of Material Thickness on the Response of Carbon-Fabric/Epoxy Panels to Low Velocity Impact," Compos. Sci. Technol., Vol. 59, No. 15, 1999, pp. 2279-2286, https://doi. org/10.1016/S0266-3538(99)00079-2

[8] Naik, N. K. and Chandra Sekher, Y., "Damage of Laminated Composites Due to Low Velocity Impact,” J. Reinf. Plast. Compos., Vol. 17, No. 14, 1998, pp. 132-1263, https://doi.org/10.1177/073168449801701401

[9] Abrate, S., "Impact on Laminated Composite Materials," Appl. Mech. Rev., Vol. 44, No. 4, 1991, pp. 155-190, https://doi.org/10.1115/1.3119500

[10] Dost, E. F., Ilcewitz, L. B., Avery, W. B., and Coxon, B. R., "Effects of Stacking Sequence on Impact Damage Resistance and Residual Strength for QuasiIsotropic Laminates," Composite Materials: Fatigue and Fracture (Third Volume), ASTM STP1110, T. K. O’Brien, Ed., ASTM International, West Conshohocken, PA, 1991, pp. 476-500.

[11] Choi, H. Y. and Chang, F. K., "A Model for Predicting Damage in Graphite/ Epoxy Laminated Composites Resulting from Low-Velocity Point Impact," J. Compos. Mater., Vol. 26, No. 14, 2016, pp. 2134-2169, https://doi.org/10.1177/ 002199839202601408

[12] Cantwell, W. J. and Morton, J., "An Assessment of the Residual Strength of an Impact Damaged Carbon Fibre Reinforced Epoxy," Compos. Struct., Vol. 14, No. 4, 1990, pp. 303-317, https://doi.org/10.1016/0263-8223(90)90012-4

[13] Siow, Y. P. and Shim, V. P. W., "An Experimental Study of Low Velocity Impact Damage in Woven Fiber Composites," J. Compos. Mater., Vol. 32, No. 12, 2016, pp. 1178-1202, https://doi.org/10.1177/002199839803201203

[14] Bucinell, R. B., Nuismer, R. J., and Koury, J. L., "Response of Composite Plates to Quasi-Static Impact Events," Composite Materials: Fatigue and Fracture (Third Volume), ASTM STP1110, T. K. O'Brien, Ed., ASTM International, West Conshohocken, PA, 1991, pp. 528-549.

[15] Robinson, P. and Davies, G. A. O., "Impactor Mass and Specimen Geometry Effects in Low Velocity Impact of Laminated Composites," Int. J. Impact Eng., Vol. 12, No. 2, 1992, pp. 189-207, https://doi.org/10.1016/0734-743X(92)90408-L

[16] Cantwell, W. J. and Morton, J., "Impact Perforation of Carbon Fibre Reinforced Plastics," Compos. Sci. Technol., Vol. 38, No. 2, 1990, pp. 119-141, https://doi. org/10.1016/0266-3538(90)90002-M

[17] Botelho, E. C., Pardini, L. C., and Rezende, M. C., "Hygrothermal Effects on the Shear Properties of Carbon Fiber/Epoxy Composites," J. Mater. Sci., Vol. 41, No. 21, pp. 7111-7118, https://doi.org/10.1007/s10853-006-0933-7

[18] Choi, H. S., Ahn, K. J., Nam, J.-D., and Chun, H. J., "Hygroscopic Aspects of Epoxy/ Carbon Fiber Composite Laminates in Aircraft Environments," Composites Part A, Vol. 32, No. 5, 2001, pp. 709-720, https://doi.org/10.1016/S1359-835X(00)00145-7

[19] Zai, B. A., Park, M. K., Choi, H. S., Mehboob, H., and Ali, R., "Effect of Moisture Absorption on Damping and Dynamic Stiffness of Carbon Fiber/Epoxy Composites," J. Mech. Sci. Technol., Vol. 23, No. 11, pp. 2998-3004, https://doi. org/10.1007/s12206-009-0908-0 
2018-06-19

\section{Low-velocity impact characterization of fiber-reinforced composites with hygrothermal effect}

\section{Zai, Behzad Ahmed}

ASTM

Khan S, Nisar S, Shah A, (2019) Low-velocity impact characterization of fiber-reinforced composites with hygrothermal effect. Journal of Testing and Evaluation, Volume 47, Issue 1, pp. 350-360 https://doi.org/10.1520/JTE20170620

Downloaded from Cranfield Library Services E-Repository 